\title{
Expression of functional CXCR4 chemokine receptors on human colonic epithelial cells
}

\author{
Nicola J. Jordan, ${ }^{1}$ George Kolios, ${ }^{1}$ Stewart E. Abbot, ${ }^{1}$ Michael A. Sinai, ${ }^{2}$ \\ Darren A. Thompson, ${ }^{2}$ Kalliopi Petraki, ${ }^{3}$ and John Westwick ${ }^{1}$
}

${ }^{1}$ School of Pharmacy and Pharmacology, University of Bath, Bath BA2 7AY, United Kingdom
2Gryphon Sciences, 250 East Grand Avenue, San Francisco, California 94080, USA
${ }^{3}$ Hippokration General Hospital, Athens GR-11527, Greece

Address correspondence to: Nicola J. Jordan, Department of Pharmacology, University of Bath, Bath BA2 7AY, United Kingdom. Phone: 01225-826826; Fax: 01225-826114; E-mail: N.J.Jordan@bath.ac.uk.

Received for publication March 2, 1999, and accepted in revised form September 1, 1999.

\begin{abstract}
In addition to their role as regulators of leukocyte migration and activation, chemokines and their receptors also function in angiogenesis, growth regulation, and HIV-1 pathogenesis - effects that involve the action of chemokines on nonhematopoietic cells. To determine whether chemokine receptors are expressed in human colonic epithelium, HT-29 cells were examined by RT-PCR for the expression of the chemokine receptors for lymphotactin, fractalkine, CCR1-10, and CXCR1-5. The only receptor consistently detected was CXCR4 (fusin/LESTR), although HT-29 cells did not express mRNA for its ligand, stromal cell-derived factor (SDF-1 $\alpha$ ). Flow cytometric analysis with anti-CXCR4 antibody indicated that the CXCR 4 protein was expressed on the surface of roughly half of HT-29 cells. CXCR4 was also expressed in colonic epithelial cells in vivo as shown by immunohistochemistry on biopsies from normal and inflamed human colonic mucosa. The mRNA for SDF- $1 \alpha$ and other CC and CXC chemokines was present in normal colonic biopsies. The CXCR4 receptor in HT-29 cells was functionally coupled, as demonstrated by the elevation in $\left[\mathrm{Ca}^{2+}\right]_{\mathrm{i}}$, which occurred in response to $25 \mathrm{nM} \mathrm{SDF}-1 \alpha$ and by the SDF-1 $\alpha$-induced upregulation of ICAM-1 mRNA. Sodium butyrate downregulated CXCR 4 expression and induced differentiation of HT-29 cells, suggesting a role for CXCR4 in maintenance and renewal of the colonic epithelium. This receptor, which also serves as a coreceptor for HIV, may mediate viral infection of colonic epithelial cells.
\end{abstract}

J. Clin. Invest. 104:1061-1069 (1999).

\section{Introduction}

Colonic epithelial cells are increasingly recognized to play an important role in host defense against microorganisms in the intestinal lumen and in inflammatory responses. Epithelial cells have been shown to have receptors for a number of proinflammatory cytokines including IL- $1 \alpha$, TNF- $\alpha$, and IFN- $\gamma$ that can induce the production of inflammatory mediators such as the chemokines, which are upregulated in inflammatory bowel conditions $(1,2)$.

Chemokines are a family of chemoattractant proteins that are classified into 4 groups, depending on the arrangement of amino acids adjacent to conserved cysteine residues. In the $\mathrm{CC}$ chemokine family, the conserved cysteine residues are adjacent. Members of this group are mainly monocyte and T-cell chemoattractants and include MCP-1, MIP-1 $\alpha$, RANTES, and eotaxin. Lymphotactin is a unique lymphocyte chemoattractant with a single conserved cysteine (3), and fractalkine, a monocyte and T-cell chemoattractant that exists as a cell-bound and soluble form, is the sole member of the CXXXC family (4). The chemokines IL-8, PF-4, IP-10, Mig, and SDF- $1 \alpha$ contain a $\mathrm{CXC}$ motif and are further subdivided depending on the presence or absence of a 3-amino acid domain (glu-leu-arg, the ELR motif). ELR-containing chemokines are neutrophil chemoattractants and potent angiogenic factors. The non-ELR chemokines (IP-10, Mig, and SDF-1 $\alpha$ ) chemoattract $\mathrm{T}$ cells and are generally angiostatic (5), although SDF- $1 \alpha$ can induce neovascularization (6).

Cells respond to chemokines through a family of 7 transmembrane $G$ protein-coupled receptors that are also divided into families: CCR1-10 bind the CC chemokines, CXCR1-5 bind CXC chemokines, and receptors for fractalkine and lymphotactin have also been identified. Each receptor has a distinct but overlapping ligand specificity (7).

Although originally identified for their ability to activate and chemoattract immune cells, chemokines and their receptors have now been shown to have additional important functions that extend beyond the regulation of leukocyte migration. In endothelial cells, CXC chemokines affect cell migration and consequently can function as angiogenic/angiostatic factors that have important implications for tumor growth and neovascularization (5). In smooth muscle, chemokines such as IP-10 and IL-8 can modulate proliferation and migration $(8,9)$, and MCP-1 can induce procoagulant activity that may enhance thrombosis in atherosclerotic plaques (10). MCP-1 can also inhibit the proliferation of smooth muscle cells (11) and upregulate ICAM-1 expression (12). In the rat, the chemokine TCA3 (human equivalent I309) binds to and activates smooth muscle cells and mesangial cells $(13,14)$. In glial and endothelial cells, SDF-1 $\alpha$ is a potent chemoattractant $(6,15)$. In many cases, the 
receptors responsible for these responses have been identified. Endothelial cells express CXCR1-4 and DARC chemokine receptors (16), mouse microglial cells, and astrocytes express CXCR4 (15), smooth muscle cells express CCR1 and CCR2 (17), and CXCR4 mRNA has previously been detected in the HT-29 colonic epithelial cell line (18). The ability of members of the chemokinereceptor family, including CCR3, CCR5, and CXCR4, to act as cofactors for HIV infection (19) raises the possibility that expression of these receptors in epithelium may play a role in viral infection of epithelial cells.

In this study, we have looked for chemokine-receptor expression in human colonic epithelium with regard to the potential role played by chemokine receptors in normal epithelial cell physiology and gut homeostasis, as well as in intestinal infection and inflammation.

\section{Methods}

Reagents. SDF- $1 \alpha$ was supplied by Gryphon Sciences (San Francisco, California, USA). Other chemokines and IL-1 $\beta$ were from Peprotec EC Ltd. (London, United Kingdom). TNF- $\alpha$ was a gift from Bayer (Slough, United Kingdom). All cell culture reagents and heat-inactivated FBS (HI-FBS) were from GIBCO BRL (Paisley, United Kingdom). Oligonucleotide primers were synthesized by Perkin Elmer (Applied Biosystems Warrington, United Kingdom). The 12G5 anti-CXCR4 antibody was from PharMingen (San Diego, California, USA). Standard reagents were from Sigma-Aldrich Co. (Poole, Dorset, United Kingdom) or Fisons Chemicals (Loughborough, United Kingdom).

Cell culture. HT-29 colonic epithelial cell line was obtained from the European Collection of Animal Cell Cultures (ECACC; Salisbury, Wiltshire, United Kingdom). HT-29 cells are an epithelial cell line derived from a colon adenocarcinoma that have characteristics of normal intestinal epithelium (20). The cells were passaged weekly and grown at $37^{\circ} \mathrm{C}$ in McCoy's $5 \mathrm{~A}$ medium supplemented with $10 \%$ FBS, penicillin/streptomycin (10 $\mathrm{U} / \mathrm{mL}$ and $10 \mu \mathrm{g} / \mathrm{mL}$, respectively), and Fungizone (0.5 $\mu \mathrm{g} / \mathrm{mL})$. To render cells quiescent, serum was removed 24 hours before experimentation.

Measurement of intracellular $\mathrm{Ca}^{2+}$ elevation. HT-29 cells were washed with PBS and briefly exposed to $0.05 \%$ trypsin/0.02\% EDTA to detach cells from culture flasks. Trypsin activity was quenched by washing in medium containing $10 \%$ FBS. Cells were then washed in HBSS containing $1 \mathrm{mM} \mathrm{Ca}^{2+}$ and $\mathrm{Mg}^{2+}$ and $1 \mathrm{mg} / \mathrm{mL} \mathrm{BSA}$, then loaded at $37^{\circ} \mathrm{C}$ for 30 minutes with the $\mathrm{Ca}^{2+}$-indicator dye, $5 \mu \mathrm{M}$ fura-2/AM (Calbiochem-Novabiochem, Nottingham, United Kingdom). The cells were washed and resuspended to $1-5 \times 10^{6}$ cells $\mathrm{mL}^{-1}$. The $\mathrm{Ca}^{2+}$ flux was measured in response to chemokines using a PTI dual-wavelength spectrofluorometer (Photon Technology International, Surbiton, Surrey, United Kingdom) with excitation at 340 and $380 \mathrm{~nm}$ and emission at $510 \mathrm{~nm}$. Experiments were also repeated using adherent cells with a fiber-optic light guide to illuminate a microscope slide.

$R T$-PCR. Total RNA was extracted from $5 \times 10^{6}$ HT-29 cells (or other primary human cells used as controls) into RNAzol (Tel-Test Inc., Friendswood, Texas, USA) as described by the manufacturers. Biopsies taken from uninflamed regions of human colon were collected into sterile tissue culture medium and homogenized into RNAzol within 1 hour. Poly $(A)^{+}$RNA was purified using a Quick Prep micro-purification kit (Amersham Pharmacia Biotech, St Albans, Hertfordshire, United Kingdom). One hundred nanograms of mRNA was denatured at $70^{\circ} \mathrm{C}$ for 10 minutes in the presence of $5 \mu \mathrm{M}$ oligo(dT) $)_{12-18}$ primer. It was then reverse transcribed in a $10-\mu \mathrm{L}$ volume with Superscript II (GIBCO BRL), $1 \times$ RT buffer, $1 \mathrm{mM}$ deoxyribonucleotide triphosphates (dNTPs), $5 \mathrm{mM}$ dithiothreitol (DDT), and $2.5 \mathrm{U} / \mu \mathrm{L}$ RNAsin (Promega Corp., South-

Table 1

PCR primers

\begin{tabular}{|c|c|c|c|c|}
\hline Probe & Product length (bp) & Sense primer sequence & Antisense primer sequence & Accession no. \\
\hline CCR1 & 327 & ACCTGCAGCCTTCACTTTCCTCAC & GGCGATCACCTCCGTCACTTG & L09230 \\
\hline CCR2 & 255 & CCAACTCCTGCCTCCGCTCTA & CCGCCAAAATAACCGATGTGATAC & U03882 \\
\hline CCR3 & 315 & TGGCGGTGTTTTTCATTTTC & CCGGCTCTGCTGTGGAT & U28694 \\
\hline $\mathrm{CCR} 4$ & 349 & GAAGAAGAACAAGGCGGTGAAGAT & ATGGTGGACTGCGTGTAAGATGAG & $\mathrm{X} 85740$ \\
\hline CCR5 & 280 & TGCTACTCGGGAATCATAAAAACT & TTCTGAACTTCTCCCCGACAAA & U54994 \\
\hline $\operatorname{CCR} 6$ & 266 & ATCGTAATGAAGTTGGGGTT & ATCACAAATTTCAGACCCCT & U45984 \\
\hline CCR7 & 362 & ACTCCATCATTTGTTTCGTG & TAGTATCCAGATGCCCACAC & L31581 \\
\hline $\operatorname{CCR} 9 / 10$ & 579 & CAAAGTCTTCCTCCCAGTCT & ACCAAGACACAACCAATACG & U94888 \\
\hline CXCR1 & 363 & GGGGCCACACCAACCTTC & AGTGCCTGCCTCAATGTCTCC & L19591 \\
\hline CXCR2 & 385 & CCGGGCGTGGTGGTGAG & TCTGCCTTTTGGGTCTTGTGAATA & M73969 \\
\hline CXCR3 & 293 & CTCCACCTAGCTGTAGCAGA & AGGAAGATGAAGTCTGGGAG & X95876 \\
\hline $\mathrm{CXCR} 4$ & 206 & TTCTACCCCAATGACTTGTG & ATGTAGTAAGGCAGCCAACA & X71635 \\
\hline CXCR5 & 465 & АтстTстTсстстGстGGTC & GTTCCTCTAGCTACCCCAAA & X68149 \\
\hline Lymphotactin $\mathrm{R}$ & 343 & CСTTTCCAAAGTGCTAGGAT & GTCATGATGGTCAGGAAGAA & L36149 \\
\hline Fractalkine $\mathrm{R}$ & 488 & AACAAATTTTCTTGGCTTCC & CCATCACTCGTGTGGTAAGT & U20350 \\
\hline $\mathrm{SDF}-1 \alpha$ & 132 & AGAGATGAAAGGGCAAAGAC & CGTATGCTATAAATGCAGGG & U19495 \\
\hline IL -8 & 562 & TGGGTGCAGAGGGTTGTG & CAGACTAGGGTTGCCAGATTTA & M28130 \\
\hline $\mathrm{MCP}-1$ & 177 & AGGAAGATCTCAGTGCAGAGG & AGTCTTCGGAGTTTGGGTTTG & $\mathrm{X} 14768$ \\
\hline $\mathrm{MCP}-3$ & 216 & ACTGAACTGAAAACAAGCCA & TCCAAGGCTTTATGTTCAAA & X72308 \\
\hline $\mathrm{MCP}-4$ & 255 & AGCTGGAGTACGTGAAATGA & AGCTCATAGTGGAAGGGAAG & AJ0001634 \\
\hline MIP $-1 \alpha$ & 257 & GCTGACTACTTTGAGACGAGC & CCAGTCCATAGAAGAGGTAGC & M23452 \\
\hline IP -10 & 229 & CCTGCTTCAAATATTTCCСT & CCTTCCTGTATGTGTTTGGA & x02530 \\
\hline MIG & 214 & AAGAAGCACGTGGTAAAACA & TCTCGGTGGCTATCTTGTTA & $\times 72755$ \\
\hline RANTES & 583 & GCTGTCCGTTTGATTTTTGTC & TGCTCATTCATCTTCTTTCTA & M21121 \\
\hline
\end{tabular}




\section{Figure 1}

Expression of chemokine receptor mRNA in HT-29 cells. PCR analysis was performed using primers against the chemokine receptors CCR1-9/10 and CXCR1-5 with GAPDH as a housekeeping probe as described in Methods. A mixed leukocyte preparation (or Jurkats) was used as a positive control, as shown in the top panel. HT-29 cells expressed CXCR4, as shown in the middle panel, and the negative control (HT-29 mRNA, which was not reverse transcribed) was consistently negative, as shown in the bottom panel. The experiment shown is representative of at least 3 independent experiments.

hampton, United Kingdom) at $42^{\circ} \mathrm{C}$ for 60 minutes. One-microliter aliquots of cDNA were PCR amplified in a $25-\mu \mathrm{L}$ reaction, containing $1 \times$ PCR buffer and $2 \mathrm{mM}$ $\mathrm{MgCl}_{2}, 0.2 \mathrm{mM}$ dNTPs, $0.5 \mu \mathrm{M}$ sense and antisense primers, and $0.4 \mathrm{U}$ High Fidelity Expand polymerase (Roche Molecular Biochemicals, Lewes, Sussex, United Kingdom). The oligonucleotide sequence and product size for each gene-specific primer pair used are shown in Table 1 . The conditions for amplification were: 5 minutes at $94^{\circ} \mathrm{C}, 30$ cycles of 30 seconds at $94^{\circ} \mathrm{C}, 30$ seconds at $56^{\circ} \mathrm{C}$ or $60^{\circ} \mathrm{C}, 30$ seconds at $72^{\circ} \mathrm{C}$, followed by an extension for 7 minutes at $72^{\circ} \mathrm{C}$. PCR products were resolved by electrophoresis on $2 \%$ agarose gels and viewed by ethidium bromide staining. Because chemokine-receptor genes do not contain intron sequences to control for genomic contamination, an identical parallel PCR reaction was performed containing starting material that had not been reverse transcribed.

Flow cytometry. HT-29 cells were detached from the culture flasks by brief exposure to $0.05 \%$ trypsin/ $0.02 \%$ EDTA and washed with PBS containing $1 \%$ FBS/0.1\% sodium azide. The cells were incubated at room temperature for 1 hour with $10 \mu \mathrm{g} / \mathrm{mL}$ anti-CXCR4 antibody (clone 12G5; PharMingen) or an isotype-matched control antibody. Cells were washed 3 times with PBS/1\%FBS/ $0.1 \%$ azide, then incubated with 1:1000 dilution of an anti-mouse IgG2a fluorescein isothiocyanate-conjugated antibody (SigmaAldritch) for 30 minutes. The cells were washed again and analyzed by flow cytometry on a FACS Vantage cell sorter (Becton Dickinson, Oxford, United Kingdom), using excitation at $488 \mathrm{~nm}$ and fluorescence emission at $520 \mathrm{~nm}$.

Northern blotting analysis. Total RNA was extracted from HT-29 cells in RNAzol as described above. Approximately $10 \mu \mathrm{g}$ of RNA was loaded per lane of a $1 \%$ agarose/formaldehyde gel. RNA was transferred to nylon membranes by capillary blotting and fixed by baking at $120^{\circ} \mathrm{C}$. Membranes were hybridized overnight at $42^{\circ} \mathrm{C}$ with a digoxigenin-labeled probe against CXCR4 (Eurogentech, Abington, United Kingdom), ICAM-1, or $\beta$-actin (R\&D Systems Europe Ltd., Abington, United Kingdom). Unbound probe was removed by washing for 10 minutes in $2 \times \mathrm{SSC}(0.3 \mathrm{M} \mathrm{NaCl}, 0.03 \mathrm{M}$ sodium citrate, $\mathrm{pH} 7.0)$ and for 10 minutes in $0.1 \times \mathrm{SSC}(15 \mathrm{mM} \mathrm{NaCl}, 1.5 \mathrm{mM}$ sodium citrate, $\mathrm{pH}$ 7.0). Bound probe was detected using anti-DIG Fab conjugated to alkaline phosphatase and a chemilumi- nescent substrate, CSPD (Roche Molecular Biochemicals), which was detected by exposure to $\mathrm{x}$-ray film.

Immunohistochemistry. Colonic biopsy specimens of normal bowel mucosa from patients undergoing colonoscopy for diverticular disease $(n=6)$, colon adenocarcinoma $(n=9)$, and from normal individuals $(n=$ $5)$ were studied immunohistochemically for the presence of CXCR4 chemokine receptor in human colonic epithelium. In routine histologic examination, these samples had normal epithelium and normal number of goblet cells; the morphology and number of glands were normal and did not show any inflammatory infiltration of the lamina propria (21).

In addition, biopsy specimens of inflamed colonic mucosa from ulcerative colitis (UC) patients $(n=14)$ undergoing diagnostic colonoscopy were studied for CXCR4 expression. All UC patients were newly diagnosed with moderate to severe disease activity at the time of colonoscopy. Patients were examined before treatment, and biopsy samples were taken from the areas of greatest involvement of the inflammatory process. Routine histology of these specimens demonstrated ulceration, mucin depletion, deformation of the glands, crypt abscesses, and inflammatory infiltration of the lamina propria (21).

Purified mouse anti-human $\mathrm{mAb}$ against the fusin/CXCR4 chemokine receptor was used in a streptavidin/biotin method to demonstrate the presence of CXCR4 in human colonic epithelium. Biopsy samples that had been fixed in formalin and embedded in paraffin were mounted on 3-amino-propyltriethoxylsilane-coated slides. Dewaxed paraffin sections were placed in a pressure cooker containing $0.01 \mathrm{M}$ buffered sodium citrate solution ( $\mathrm{pH}$ 6), boiled for 2 minutes, and chilled to room temperature to recover antigens (22). The mounted slides were then incubated for 1 hour at room temperature with anti- 
human CXCR4 antibody diluted 1:100 (10 mg/mL). Harris hematoxylin was used as a counterstain. Control sections from adjacent sections were stained with mouse $\mathrm{IgG}_{2 \mathrm{a}}$ isotype-matched antibody (Sigma) under the same conditions to determine the specificity of antibody binding.

\section{Results}

Differential expression of chemokine receptor mRNA in HT-29 cells. RT-PCR was performed on serum-starved HT-29 cells using primers for the chemokine receptors CCR1-CCR10, CXCR1-CXCR5, and the receptors for lymphotactin and fractalkine. Primer pairs were validated by examining their expression in leukocytes prepared from human blood or in the Jurkat cell line (for CCR8 and CCR9/10). Figure 1 shows the results of a representative experiment that was repeated at least 3 times with cells of different passage numbers. The only receptor to be consistently expressed after 30 cycles of PCR using the conditions shown in the Methods section, was the SDF- $1 \alpha$ receptor, CXCR4 (fusin/LESTR). The PCR product was sequenced and shown to be identical to the expected CXCR4 sequence. None of the other chemokine-receptor mRNAs examined were consistently detected. Identical results were obtained when these experiments were repeated using non-serumstarved HT-29 cells (not shown).

CXCR4 protein is expressed on the surface of HT-29 cells. The cell-surface expression of CXCR4 was evaluated by FACS analysis of HT-29 cells using a specific antibody against CXCR4 (Figure 2). There was a shift in the fluorescence intensity of the cells that had been treated with anti-CXCR4, compared with an isotype control antibody. In 3 independent experiments, CXCR4 was expressed by $48 \pm 7 \%$ (mean \pm SD) of HT- 29 cells. The same percentage of cells stained regardless of whether the cells were growing or quiescent.

Effect of CXC and CC chemokines on change in $\left[\mathrm{Ca}^{2+}\right]_{i}$ in HT29 cells. To determine whether HT-29 cells express any functional chemokine receptors, chemokines were investigated for their ability to induce changes in $\left[\mathrm{Ca}^{2+}\right]_{i}$. Chemokine-stimulated elevation of cytosolic $\left[\mathrm{Ca}^{2+}\right]_{i}$ is a characteristic response of most leukocyte chemokine receptors. A large increase in transient $\mathrm{Ca}^{2+}$ elevation was induced in HT-29 cells in response to $12.5 \mathrm{nM} \mathrm{SDF}-1 \alpha$, the ligand for CXCR4 (Figure 3a). A number of other chemokines were also tested at $12.5 \mathrm{nM}$, including IP-10, Mig, MIP-1 $\alpha$, MCP-1, IL-8, RANTES, and eotaxin; none of them produced a response. This was consistent with the absence of mRNA by RT-PCR analysis (results not shown). The response to SDF- $1 \alpha$ was concentration-dependent, with an optimum elevation of $\left[\mathrm{Ca}^{2+}\right]_{\mathrm{i}}$ of $89 \pm 12.6 \mathrm{nM}$ (mean \pm SEM, $n=14$ ) with 25 nM SDF- $1 \alpha$ (Figure 3b).

SDF-1 $\alpha$ induces ICAM-1 mRNA expression in HT-29 cells. Although indicating that the CXCR4 receptors on HT29 cells are able to signal, measurement of the increased transient $\mathrm{Ca}^{2+}$ does not indicate what the functional outcome may be in the epithelial cell. We therefore looked to see whether SDF- $1 \alpha$, the only known ligand for CXCR4, could induce any factors that may be associated with inflammatory processes.

Colonic epithelial cell lines express a low basal level of the intercellular adhesion molecule ICAM-1, which can be upregulated by proinflammatory cytokines. We have used Northern analysis to determine whether SDF- $1 \alpha$ could also upregulate ICAM-1 expression. As shown in Figure 4, 25 nM SDF- $1 \alpha$ enhanced ICAM- 1 mRNA expression after 6 hours, with a peak expression after 24-hour exposure.

Sodium butyrate inhibits CXCR4 mRNA expression in HT-29 cells. Because SDF- $1 \alpha$ is expressed in the colon constitutively we considered the possibility that SDF- $1 \alpha$ and CXCR4 may play a role in maintaining the normal colon physiology. The colon is a constantly renewing tissue and, as such, epithelial cell proliferation must be strictly controlled. Maintenance of cell numbers requires a balance between proliferation, differentiation, and apoptosis. This balance is controlled by endogenous factors and may be influenced by dietary factors such as the short-chain fatty acid butyrate, which is a fermentation product of dietary fiber. A 24-hour treatment with $5 \mathrm{mM}$ sodium butyrate caused an increased activity of the brush border enzyme alkaline phosphatase in HT-29 cells (results not shown). This indicated that the cells were starting to differentiate. Northern analysis showed that expression of the $1.8-\mathrm{kb}$ CXCR4 mRNA transcript was completely inhibited by treatment with $5 \mathrm{mM}$ butyrate over a time course from 3 to 24 hours. Expression of the housekeeping gene $\beta$-actin was not affected (Figure 5).

Chemokine expression in normal buman colon and HT-29 cells. We have shown previously that HT-29 cells stimulated with proinflammatory cytokines can secrete a number of chemokines including IL-8, MCP-1, and RANTES (23). When analyzed by 35 cycles of RT-PCR, unstimulated, serum-starved HT-29 cells were found to express MCP-1, MCP-3, MIP-1 $\alpha$, IL-8, and IP-10 with very low expression of Mig and SDF- $1 \alpha$ mRNA. Upon stimulation with IL- $1 \alpha$, TNF- $\alpha$, and IFN- $\gamma$, stronger bands were detected for MCP-1, IL-8, and Mig. The chemokines MCP-4 and SDF- $1 \alpha$ were present as weak bands or nor at all. Thus, HT-29 cells have the CXCR4 receptor but do

\section{Figure 2}

Surface expression of CXCR4 on HT-29 cells. HT-29 cells were incubated with $10 \mu \mathrm{g} / \mathrm{mL}$ anti-CXCR4 (filled) or an isotype control antibody (open), then labeled with a FITC conjugate. Washed cells were analyzed by flow cytometry in which accumulated events were gated against the isotype control. The experiment shown is representative of 3 similar experiments.

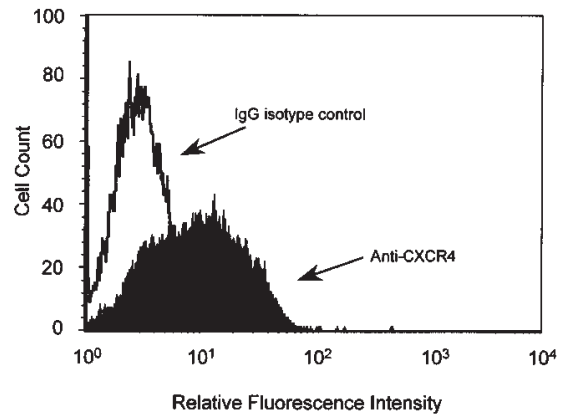


a

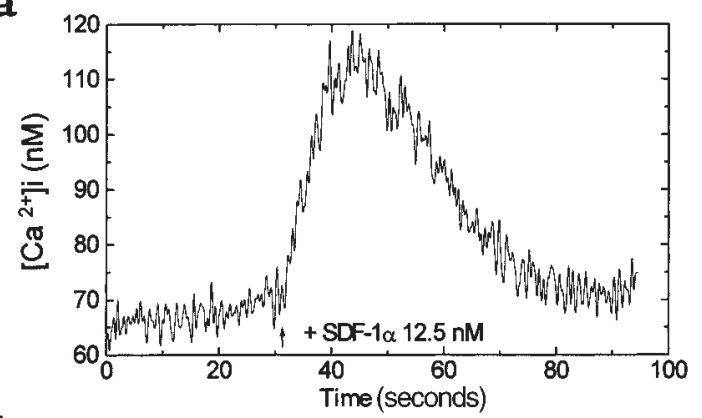

b

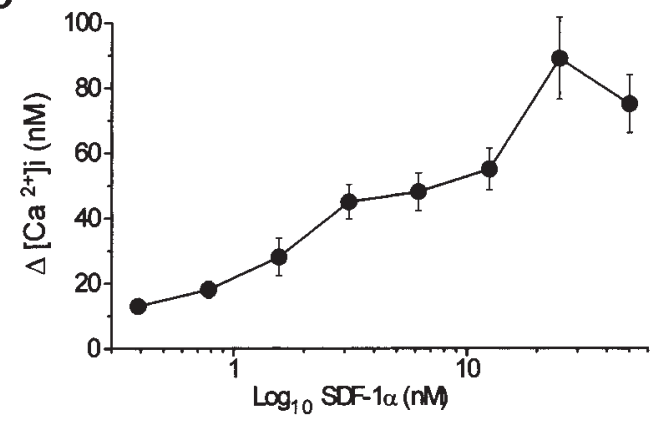

Figure 3

$\mathrm{Ca}^{2+}$ flux in HT-29 cells in response to SDF-1 $\alpha$. (a) The elevation of intracellular $\mathrm{Ca}^{2+}$ induced in fura-2/AM-loaded HT-29 cells in response to stimulation with $12.5 \mathrm{nM}$ SDF- $1 \alpha$. (b) The response to SDF- $1 \alpha$ is concentration-dependent. Aliquots of fura-2/AM-loaded HT-29 cells were stimulated with SDF- $1 \alpha$ at concentrations from 0.4 to $50 \mathrm{nM}$. Results are the mean $\left[\mathrm{Ca}^{2+}\right]_{i}$ for 3-14 measurements ( \pm SEM).

not express its ligand, SDF-1 $\alpha$ (Figure 6). SDF- $1 \alpha$ mRNA also could not be detected in a preparation of human white blood cells, nor was it expressed by purified T cells or T blasts (data not shown). A major source of SDF-1 $\alpha$ mRNA is human bone marrow stromal cells that are known to produce this chemokine constitutively (24).

Chemokine expression was also investigated in normal human colonic biopsies; the results are shown in the bottom 2 panels of Figure 6 . The following chemokines could be detected in colonic specimens: MCP-1, MCP-3, MCP-4, RANTES, MIP-1 $\alpha$, IP-10, Mig, and SDF- $1 \alpha$. IL8 was not expressed in this uninflamed tissue. The CXCR4 receptor could also be detected. The presence of SDF- $1 \alpha$ mRNA in colonic tissue indicates that in vivo epithelial cells will probably be exposed to the ligand for CXCR4. Differences between the HT-29 epithelial cells and the biopsies may reflect the fact that biopsy specimens contain other cell types in addition to epithelial cells, mainly fibroblasts and intraepithelial T cells.

Normal buman colonic epithelial cells express CXCR4 protein. To determine whether the expression of CXCR4 seen in HT-29 cells was unique to this cancerous cell line or a characteristic of "real" colonic epithelium as well, human colonic biopsies were stained with an antibody against CXCR4. In all cases of uninflamed colonic mucosa studied $(n=20)$, the colonic epithelial cells expressed appreciable amounts of CXCR4 chemokine receptor at the surface of the mucosa and the crypts. Interestingly, the staining was strongest in the epithelial cells at the base of the crypt (Figure 7, a and b). CXCR4 expression was also observed in leukocytes of the lamina propria, as was expected, and endothelial cells, as has been described previously (25). In addition, in all cases $(n=14)$ of inflamed mucosa from ulcerative colitis patients, colonic epithelial cells expressed CXCR4; again, staining was strongest in the crypt cells. The ulcerative colitis patients had a large inflammatory infiltration of the mucosa, and many CXCR4 positive cells were observed here (Figure 7c). No staining was seen in adjacent sections when an isotype control antibody was used (Figure $7 d$ ). In addition to the specimens of large bowel, biopsies from the adjacent terminal ileum were also studied. Intestinal epithelial cells from the small bowel also expressed the CXCR4 chemokine receptor (Figure 7e).

\section{Discussion}

Epithelial cells line the mucosal surface of the colon and form a mechanical barrier that separates the host from the external environment. In addition to providing a surface for absorption, epithelial cells also secrete and respond to a number of inflammatory mediators, thus enabling communication with cells of the immune system and ensuring that inflammatory responses are mounted against ingested pathogens.

In previous studies, we have shown that colonic epithelial cells exposed to the proinflammatory cytokines IL-1 and TNF- $\alpha$ can secrete chemokines such as IL-8, MCP-1, and RANTES (23). Here we have shown that mRNA for many chemokines from both the CC and the CXC families is expressed in uninflamed human colon. Some of these chemokines may be responsible for the recruitment of the specialized subset (mainly $\mathrm{CD}^{+}$and $\mathrm{CD}^{+}$) of

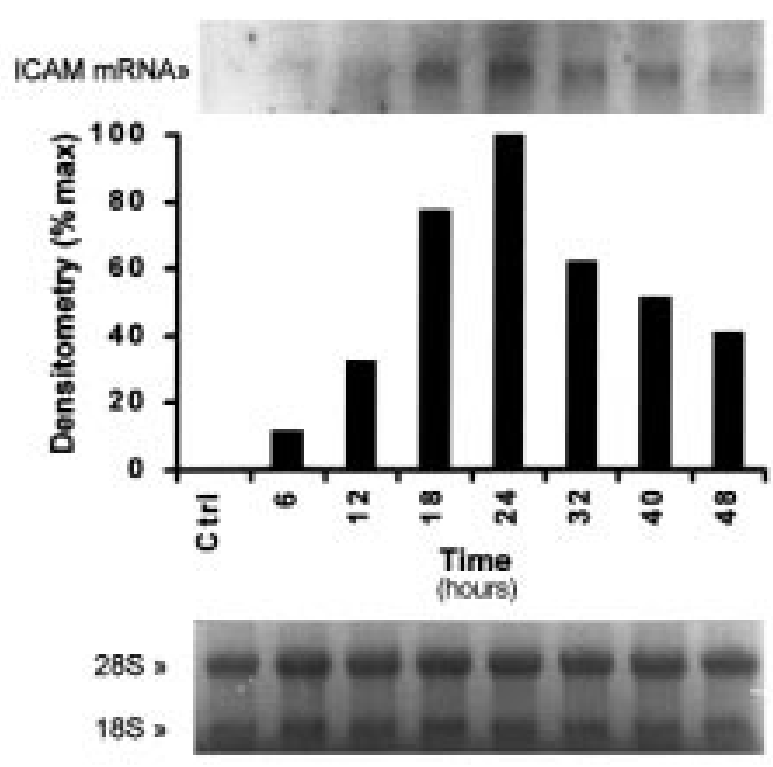

Figure 4

SDF-1 $\alpha$ enhances ICAM- 1 mRNA expression in HT- 29 cells. HT- 29 cells were serum starved for 24 hours, then treated between 1 and 48 hours with 25 nM SDF-1 $\alpha$, before RNA was extracted. Blots were probed for ICAM-1 mRNA. Densitometric analysis shows maximum expression at 24 hours. Equal loading is shown by the ethidium bromide staining of the $18 \mathrm{~S}$ and $28 \mathrm{~S}$ ribosomal RNA (bottom panel). The result shown is representative of 2 similar experiments. 


\section{Figure 5}

CXCR4 mRNA expression in HT-29 cells is reduced by sodium butyrate. HT-29 cells were serum starved for 24 hours and then stimulated with $1 \mathrm{mM}$ or $5 \mathrm{mM}$ sodium butyrate as shown for 3-24 hours. RNA was extracted as described in Methods and analyzed by Northern blotting. Blots were probed for CXCR4 mRNA (top panel) and $\beta$-actin to demonstrate equal loading. The result shown is representative of 3 similar experiments.
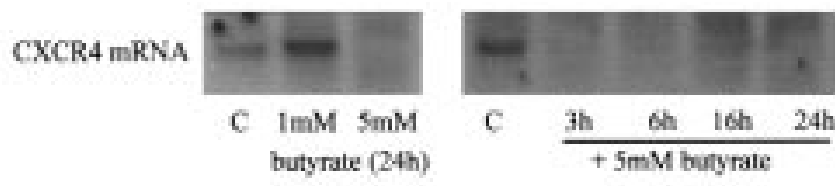

$\beta$-sctin mRNA
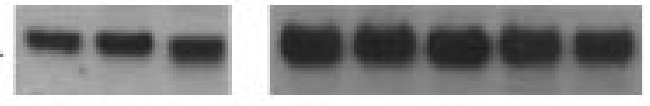

intraepithelial T cells, which can constitute up to $15 \%$ of the normal uninflamed human colonic epithelium (26). These $T$ cells, together with the colonic epithelial cells, are the first to come into contact with intestinal antigens and are thought to play a role in immune surveillance. Increased production of chemokines has also been reported in colonic mucosa from patients with inflammatory bowel disease (27), which may be associated with enhanced influx of intestinal intraepithelial lymphocytes (28). Interestingly, we did not detect IL-8 mRNA in the normal colon, though it can be produced by cytokinestimulated epithelial cells. Its role is probably in neutrophil recruitment, which occurs during acute inflammation. Chemokines produced from activated leukocytes, fibroblasts, or epithelial cells probably play a role in leukocyte recruitment for surveillance or in inflammation in the gut.

In the present study, we have investigated whether colonic epithelial cells are targets for autocrine or paracrine regulation by the wide array of chemokines produced by cells in the colonic mucosa. Our results have shown that the HT-29 epithelial cell line only expresses mRNA for one of the known chemokine receptors, CXCR4. This receptor was expressed as a protein at the cell surface on about $50 \%$ of HT-29 cells and was functional, as shown by a $\mathrm{Ca}^{2+}$ flux induced by its ligand, SDF$1 \alpha$. Other chemokines from the CXC and CC families failed to induce any change in $\mathrm{Ca}^{2+}$ flux in HT-29 cells consistent with the absence of mRNA for their receptors. These colonic epithelial cells express fewer chemokine receptors than endothelial cells, which express mRNA for CXCR1-4 (16). CXCR4 mRNA was, however, abundantly expressed in unstimulated HT-29 cells, as shown by the ability to detect mRNA transcripts by Northern analysis; CXCR4 mRNA has also been shown to be the most abundant chemokine receptor expressed in vascular endothelium (25). We also demonstrated that CXCR4 is not only found on the HT-29 cell line, but is also present in epithelial cells of normal and inflamed colon and small bowel.

Further evidence that CXCR4 was functional was obtained by measuring the increased expression of the intercellular adhesion molecule, ICAM-1, in HT-29 cells in response to stimulation with SDF- $1 \alpha$.
Previously, the CC chemokine, MCP-1, has been shown to induce ICAM-1 mRNA in smooth muscle cells after 2 hours (12). In HT-29 cells, the proinflammatory cytokines, IL-1 and TNF- $\alpha$, induce ICAM- 1 mRNA expression by 2 hours (data not shown), thus the effect of SDF- $1 \alpha$ on HT- 29 cells (where ICAM-1 expression peaked at 24 hours) is delayed. This suggests that it may operate through an indirect mechanism, possibly involving production of an unknown intermediate. Alternatively, it is possible that because SDF- $1 \alpha$ is normally presented to cells by extracellular matrix proteins, it may only be fully active in this conformation, thus the extended time required to induce ICAM-1 may be because we used soluble SDF- $1 \alpha$. Although a good indicator that CXCR4 is functional, it does not necessarily follow that SDF-1 $\alpha$ upregulates ICAM-1 expression in colonic epithe-

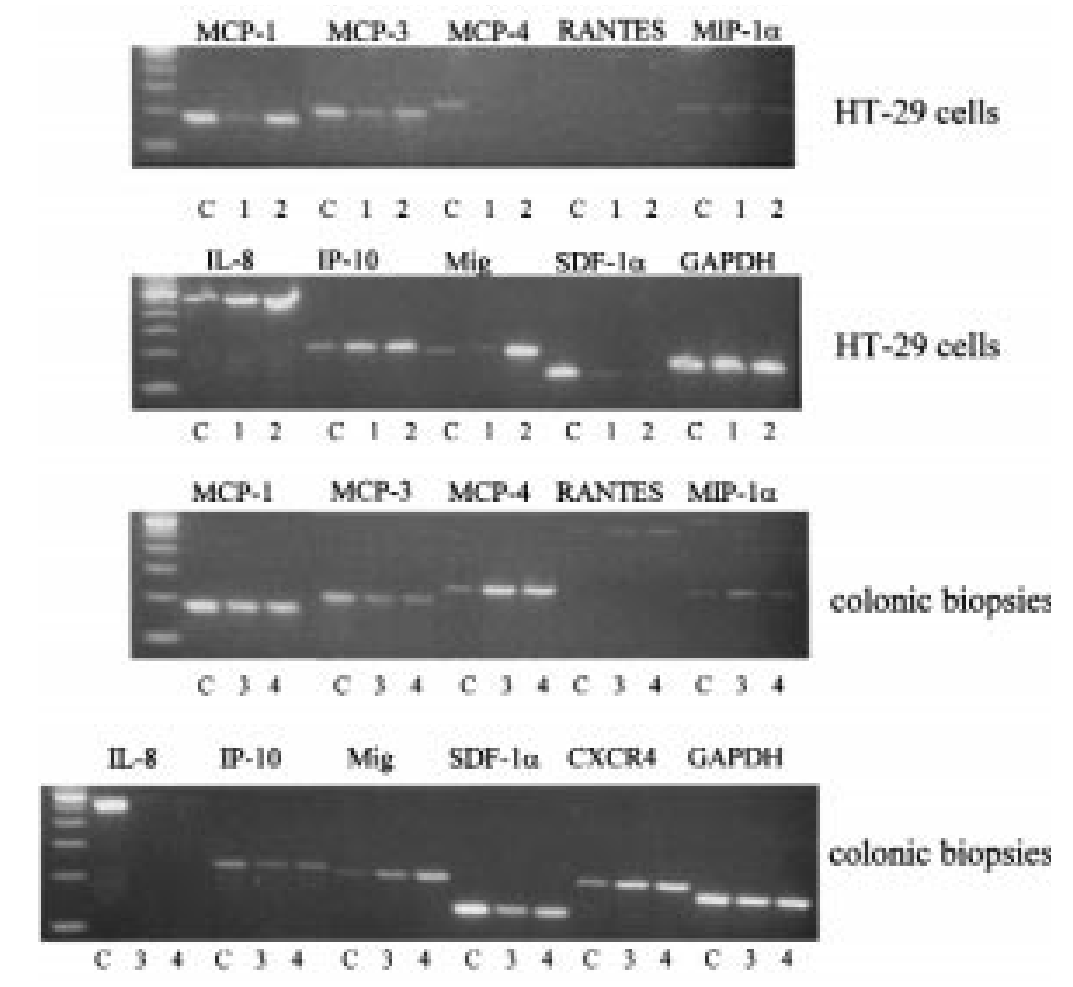

Figure 6

Chemokine expression in HT-29 cells and human colon. The top 2 panels show the expression of chemokine mRNA by colonic epithelial cells using RT-PCR analysis of treated HT-29 cells. HT-29 cells were serum starved for 24 hours, then either left untreated for an additional 6 hours (denoted by the number 1 ) or treated for 6 hours with IL- $1 \alpha$, TNF- $\alpha$, and IFN$\gamma(3 \mathrm{ng} / \mathrm{mL}, 30 \mathrm{ng} / \mathrm{mL}, 100 \mathrm{U} / \mathrm{mL}$, respectively) (denoted by the number 2$)$. The mRNA was prepared and PCR analysis performed as described in Methods. A mixed leukocyte preparation was used as a positive control (C) for all primer pairs except SDF-1 $\alpha$, where human bone marrow stromal cells were used as a positive control. The bottom 2 panels show RTPCR analysis of chemokine mRNA expression in human colonic biopsies taken from 2 patients with normal noninflamed colon (denoted by the numbers 3 and 4). 

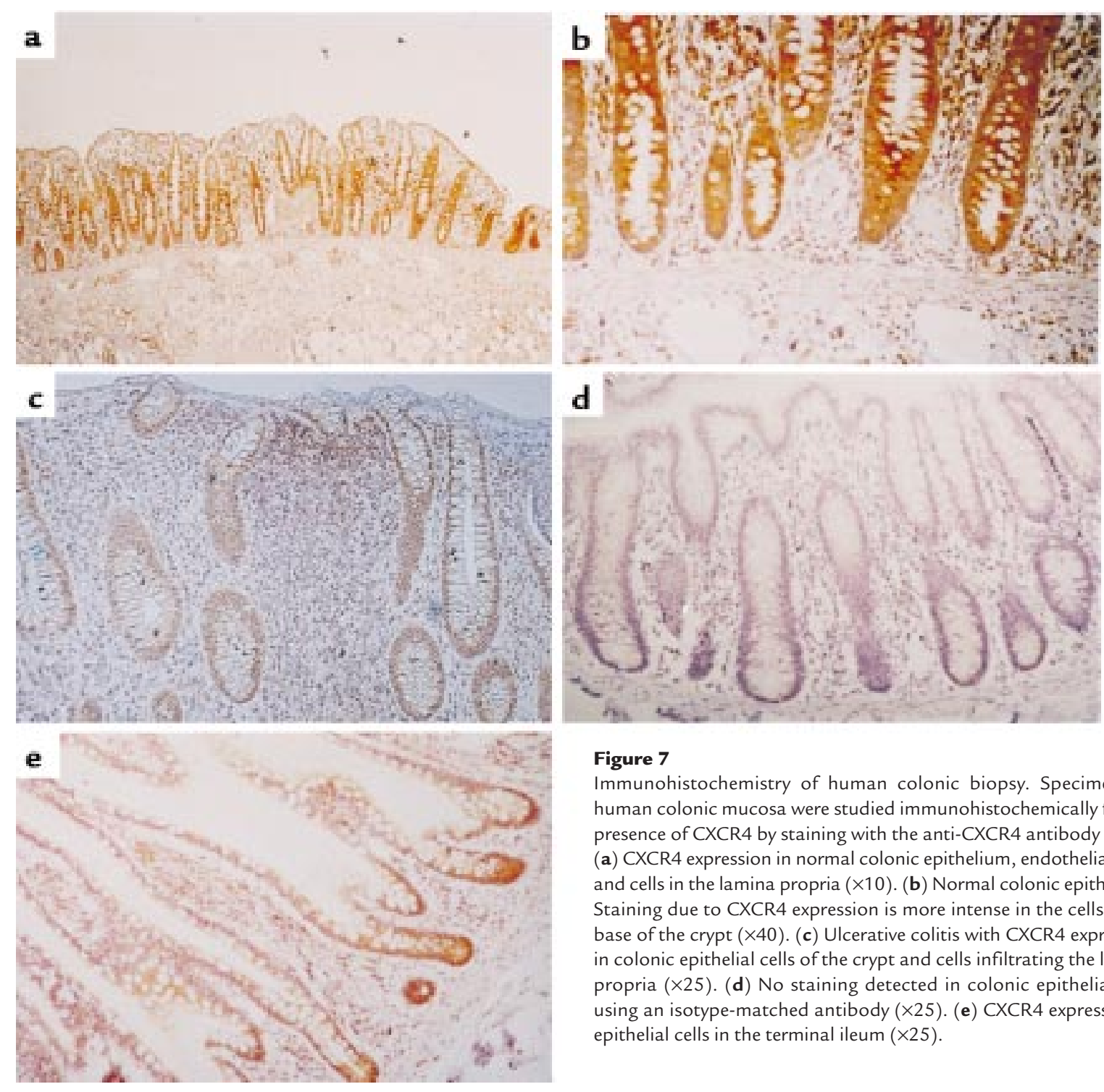

\section{Figure 7}

Immunohistochemistry of human colonic biopsy. Specimens of human colonic mucosa were studied immunohistochemically for the presence of CXCR4 by staining with the anti-CXCR4 antibody $12 \mathrm{G} 5$. (a) CXCR4 expression in normal colonic epithelium, endothelial cells, and cells in the lamina propria $(\times 10)$. (b) Normal colonic epithelium. Staining due to CXCR4 expression is more intense in the cells at the base of the crypt $(\times 40)$. (c) Ulcerative colitis with CXCR4 expression in colonic epithelial cells of the crypt and cells infiltrating the lamina propria $(\times 25)$. (d) No staining detected in colonic epithelial cells using an isotype-matched antibody $(\times 25)$. (e) CXCR4 expression in epithelial cells in the terminal ileum $(\times 25)$.

lium in vivo, although it may be a mechanism involved in recruitment of leukocytes in inflammatory bowel conditions because SDF- $1 \alpha$ can induce the arrest of rolling lymphocytes to ICAM-1 (29).

SDF- $1 \alpha$ and its receptor CXCR 4 are different in many aspects from other chemokine-receptor ligand pairs. CXCR4 is one of the few chemokine receptors for which only a single ligand has been identified so far. Although SDF- $1 \alpha$ belongs to the CXC subfamily, it is almost equally related to both CC and CXC families, and the gene is located on a different chromosome from the other CXC group members (30). The structure of the molecule consists of an unusual packing of the alpha helix against the beta sheet, suggesting that it may be the least divergent from a primordial chemokine (31). This is also supported by the similarity of the mouse and human SDF-1 $\alpha$ (32). CXCR4 is expressed constitutively in a broad range of tissues including brain, thymus, lymph nodes, spleen, stomach, kidney, and small intestine (30).

SDF- $1 \alpha$ was cloned from a bone marrow stromal cell line (32). It is not expressed by hematopoietic progenitor cells or lymphocytes, but is expressed by

fibroblasts, which may explain its expression in various organs including brain, heart, lung, kidney, thymus, spleen, and liver (32). SDF-1 $\alpha$ is expressed constitutively and does not appear to be upregulated by proinflammatory cytokines. It has, therefore, been proposed that SDF- $1 \alpha$ plays a role in immune surveillance and basal extravasation rather than in inflammation (24). The presence of TATA-less and GC-rich sequences in the $5^{\prime}$ flanking region of the SDF- $1 \alpha$ gene is consistent with it being a housekeeping gene (33). SDF- $1 \alpha$ is chemotactic for resting $T$ lymphocytes and monocytes, again supporting an immune surveillance role for this chemokine. In the gut, it may be responsible for the recruitment of intraepithelial $\mathrm{T}$ cells. SDF- $1 \alpha$, which is also known as pre-B cell growth-stimulating factor (PBSF), stimulates proliferation of B-cell progenitors (30) and is involved in B-cell migration (34), is a chemoattractant for hematopoietic progenitors and enhances adhesion of megakaryocytes to endothelium (35).

Unlike most chemokines, SDF- $1 \alpha$ plays a fundamental role in development. Deletion of the SDF-1 $\alpha$ or the CXCR 4 
gene are both embryologically lethal in mice $(36,37)$. The action of SDF- $1 \alpha$ appears to be essential for B cell lymphoiesis and bone marrow myelopoiesis, as well as for correct development of the ventricular septum. Correct vascularization of the gastrointestinal tract is also dependent on the presence of SDF- $1 \alpha$, as is fetal cerebellar development, suggesting a role for CXCR4/SDF- $1 \alpha$ neuronal cell migration and patterning in the central nervous system (38).

Because SDF- $1 \alpha$ appears to be expressed constitutively in most adult tissues, including the colon; its biological action is likely to be regulated at the level of the CXCR4 receptor. In T cells, IL-4 induced functional expression of CXCR4, thereby promoting SDF$1 \alpha$-induced migration of these cells (39). It has been shown that CXCR4 expression in endothelial cells is sensitive to regulation with IL- $1 \alpha$, TNF- $\alpha$, and IFN- $\gamma$. IFN$\gamma$ caused a rapid and sustained decrease in steady-state levels of CXCR 4 mRNA, whereas IL- $1 \alpha$, TNF- $\alpha$, and LPS mediate an immediate decrease in CXCR4, followed by a reversal and increase in steady-state levels (25). In serumstarved colonic epithelial cells and in both uninflamed and inflamed (patients with ulcerative colitis) colonic epithelial cells, we detected high constitutive levels of CXCR4, suggesting a physiological role for this receptor in normal gut homeostasis.

The role of CXCR4 in the normal colonic epithelium is not clear, but it is potentially active because its ligand, SDF$1 \alpha$, has been detected in colonic tissue both in this study and previously (33). The colonic epithelial cell line HT-29 did not express SDF- $1 \alpha$ mRNA. This may reflect the cancerous nature of the HT-29 cells because Shibuta et al. (33) have previously failed to find SDF- $1 \alpha$ (also known as human intercrine reduced in hepatomas [hIRH]) expression in a premalignant colonic adenocarcinoma and found a reduction in SDF- $1 \alpha$ expression in the majority of hepatoma and digestive tract carcinomas (including primary colon cancers) compared with that in adjacent noncancer tissue. It appears possible that SDF- $1 \alpha$ may play a role in carcinogenesis as a tumor-suppressor gene (33). This effect may be mediated by the ability of SDF- $1 \alpha$ to inhibit the neovascularization required for tumor growth, thus inhibition of SDF- $1 \alpha$ production by the tumor cells may be advantageous for tumor growth (5).

Our immunohistochemical study demonstrated that it was the epithelial cells at the base of the crypts or glands that stained most strongly for CXCR4. Because these cells are undergoing cell division and subsequent maturation, this may suggest a role for SDF- $1 \alpha$ and CXCR4 in the renewal and maintenance of the epithelium. Apoptosis is important in a colonic epithelial cell that is programmed to have a short life-span, such as cells in the crypt proliferate, those in the villus differentiate, and apoptose. CXCR4 has been shown to be the receptor that mediates the apoptotic effects of the HIV$1 \mathrm{gp} 120$. Both gp120 and SDF-1 $\alpha$ directly induce apoptosis in a human neuronal cell line (40) and in $\mathrm{CD}^{+} \mathrm{T}$ cells (41). In $\mathrm{CD}^{+} \mathrm{T}$ cells, gp-120 induces apoptosis through CXCR4, but SDF-1 $\alpha$ inhibits the cell death (42). We were unable to demonstrate that SDF- $1 \alpha$ could modulate apoptosis in HT-29 cells induced by IL-1, TNF, and IFN- $\gamma$ (results not shown), possibly because this is a transformed cell line. However, in agreement with the reduced expression of CXCR 4 in the cells of the villus, which are differentiated compared with the cells in the crypt, we found that the fatty acid, butyrate, in addition to causing HT-29 cell differentiation, also completely inhibited CXCR4 mRNA expression. This means that CXCR4 expression can potentially be regulated by dietary factors and supports the hypothesis that CXCR4 may be important in the growth of epithelial cells

An unfortunate consequence of epithelial cell CXCR4 expression is that it may mediate HIV infection. CXCR4 is one of the cofactors required for entry of the T-tropic HIV into cells $(43,44)$. The second receptor is generally CD4; however, in non-CD4-expressing cells, such as glial and colonic epithelial cells, HIV-1 uses the glycolipid galactosylceramide as a second receptor in conjunction with CXCR4 $(18,45)$. There is also evidence that CXCR4 can function alone as a primary HIV-2 viral receptor (46). Unlike the M-tropic HIV coreceptor, CCR5, which is largely restricted to cells of the hematopoietic lineage, CXCR4 is expressed on a wide variety of different cell types. M-tropic virus strains appear to be responsible for the primary infection by HIV that occurs by sexual transmission. The emergence of T-tropic strains of HIV tends to correlate with a rapid progression to AIDS. At this stage HIV infection of nonhematopoietic cells, such as neural cells through CXCR4, may lead to dementia, and HIV-1 infection of colonic epithelial cells may alter ion secretion in the intestine and thus be the causative agent of the watery diarrhea associated with HIV-1 infection (47). It is also possible that other viruses also use CXCR4 to activate epithelial cells.

In summary, this study has shown that with the exception of CXCR4, all of the known chemokine receptors are not expressed constitutively by the colonic epithelial cell line HT-29; CXCR4 is strongly expressed by both HT29 cells and real human colonic epithelium. Colonic tissue expresses SDF- $1 \alpha$, and this ligand is able to induce a $\mathrm{Ca}^{2+}$ flux in colonic epithelial cells. Further studies need to be undertaken in order to reveal the role of SDF- $1 \alpha$ and CXCR4 for epithelial cell function in vivo, though it seems probable that CXCR4 may enable HIV infection of colonic epithelium, and SDF-1-induced ICAM-1 expression on HT-29 cells may mediate intraepithelial Tcell recruitment during an inflammatory response. CXCR4 expression may also be involved in renewal and maintenance of the epithelial layer.

Note added in proof. Dwinell et al. (48) have recently reported CXCR4 expresssion in HT-29 cells and colonic epithelium.

\section{Acknowledgments}

$\mathrm{N}$. Jordan was supported by a grant from the British Heart Foundation.

\footnotetext{
1. Warhurst, A.C., Hopkins, S.J., and Warhurst, G. 1998. Interferon gamma induces differential upregulation of $\alpha$ and $\beta$ chemokine secretion in colonic epithelial cell lines. Gut. 42:208-213.

2. Yang, S.K., Eckmann, L., Panja, A., and Kagnoff, M.F. 1997. Differential and regulated expression of $\mathrm{CXC}, \mathrm{CC}$ and $\mathrm{C}$ chemokines by human colon epithelial cells. Gastroenterology. 113:1214-1223.

3. Kennedy, J., et al. 1995. Molecular cloning and functional characterisation of human lymphotactin. J. Immunol. 155:203-209.

4. Bazan, J.F., et al. 1997. A new class of membrane-bound chemokine with a CX3C motif. Nature. 385:640-644.

5. Keane, M.P., Arenberg, D.A., Moore, B.B., Addison, C.L., and Streiter, R.M.
} 
1998. CXC chemokines and angiogenesis/angiostasis. Proc. Natl. Acad. Sci. USA. 110:288-296.

6. Salcedo, R., et al. 1999. Vascular endothelial growth factor and basic fibroblast growth factor induce expression of CXCR4 on human endothelial cells. In vivo neovascularization induced by stromal-derived factor-1 alpha. Am. J. Pathol. 154:1125-1135.

7. Ward, S.G., Bacon, K., and Westwick, J. 1998. Chemokines and T-lymphocytes: more than an attraction. Immunity. 9:1-11.

8. Wang, X., Yue, T.-L., Ohlstein, E.H., Sung, C.-P., and Feuerstein, G.Z. 1996. Interferon inducible protein-10 involves vascular smooth muscle cell migration, proliferation and inflammatory response. J. Biol. Chem. 271:24286-24293.

9. Yue, T.-L., et al. 1994. Interleukin-8 a mitogen and chemoattractant for vascular smooth muscle cells. Circ. Res. 75:1-7.

10. Schecter, A.D., et al. 1997. Tissue factor is induced by monocyte chemoattractant protein-1 in human aortic smooth muscle and THP-1 cells. J. Biol. Chem. 272:28568-28573.

11. Ikeda, U., et al. 1995. Monocyte chemoattractant protein-1 inhibits growth of rat vascular smooth muscle cells. Am. J. Physiol. 268:H1021-H1026.

12. Ikeda, U., et al. 1993. Expression of intercellular-adhesion molecule-1 on rat vascular smooth muscle cells by pro-inflammatory cytokines. Atherosclerosis. 104:61-68.

13. Luo, Y., and Dorf, M.E. 1996. $\beta$ chemokine TCA3 binds to mesangial cells and induces adhesion, chemotaxis and proliferation. J. Immunol. 156:742-748.

14. Luo, Y., Damore, P.A., and Dorf, M.E. 1996. $\beta$-chemokine TCA3 binds to and activates rat vascular smooth muscle cells. J. Immunol. 157:2143-2148

15. Tanabe, S., et al. 1997. Functional expression of the CXC-chemokine receptor-4/fusin on mouse microglial cells and astrocytes. J. Immunol. 159:905-911.

16. Feil, C., and Augustin, H.G. 1998. Endothelial cells differentially express functional CXC-chemokine receptor-4 (CXCR-4/fusin) under the control of autocrine activity and exogenous cytokines. Biochem. Biophys. Res. Commun. 247:38-45.

17. Hayes, I.M., et al. 1998. Human vascular smooth muscle cells express receptors for C-C chemokines. Arterioscler. Thromb. 18:397-403.

18. Delezay, O., et al. 1997. Co-expression of CXCR4/fusin and galactosylceramide in the human intestinal epithelial cell line HT-29. AIDS. 11:1311-1318.

19. Doms, R.W., and Peiper, S.C 1997. Unwelcomed guests with master keys: how HIV uses chemokine receptors for cellular entry. Virology. 235:179-190.

20. Chantret, I., Barbat, A., Dussaulx, E., Brattain, M.G., and Zweibaum, A. 1988. Epithelial polarity, villin expression, and enterocytic differentiation of cultured human colon carcinoma cells: a survey of twenty cell lines. Cancer Res. 48:1936-1942.

21. Nostrant, T.T., Kumar, N.B., and Appelman, H.D. 1987. Histopathology differentiates acute self-limited colitis from ulcerative colitis. Gastroen terology. 92:318-328.

22. Norton, A.J., Jordan, S., and Yoemans, P. 1994. Brief high temperature heat denaturation (pressure cooking): a simple and effective method of antigen retrieval for routinely processed tissues. J. Pathol. 173:371-379.

23. Kolios, G., et al. 1999. CXC and CC chemokine expression and secretion by the human colonic epithelial cell line HT-29: differential effect of Tlymphocyte derived cytokines. Eur. J. Immunol. 29:530-536.

24. Bleul, C.C., Fuhlbrigge, R.C., Casasnovas, J.M., Aiuti, A., and Springer, T.A. 1996. A highly efficacious lymphocyte chemoattractant, stroma cell-derived factor 1 (SDF-1). J. Exp. Med. 184:1101-1109.

25. Gupta, S.K., Lysko, P.G., Pillarisetti, K., Ohlstein, E., and Stadel, J.M. 1998. Chemokine receptors in human endothelial cells. Functiona expression of CXCR4 and its transcriptional regulation by inflammatory cytokines. J. Biol. Chem. 273:4282-4287.
26. Hoang, P., Senju, M., Lowes, J.R., and Jewell, D.P. 1992. Phenotypic characterization of isolated intraepithelial lymphocytes in patients with ulcerative colitis and normal controls. Dig. Dis. Sci. 37:1725-1728.

27. Kolios, G., Petoumenos, C., and Nakos, A. 1998. Mediators of inflammation: production and implications in inflammatory bowel disease. Hepatogastroenterology. 45:1601-1609.

28. Boismenu, R., Feng, L., Xia, Y.Y., Chang, J.C.C., and Havran, W.L. 1996. Chemokine expression by intraepithelial gamma/delta T cells. Implications for the recruitment of inflammatory cells to damaged epithelia. J. Immunol. 157:985-992.

29. Campbell, J.J., et al. 1998. Chemokines and the arrest of lymphocytes rolling under flow conditions. Science. 279:381-384.

30. Nagasawa, H., Kitutani, H., and Kishimoto, T. 1994. Molecular cloning and structure of a pre-B-cell growth stimulating factor. Proc. Natl. Acad. Sci. USA. 91:2305-2309.

31. Dealwis, C., et al. 1998. Crystal structure of chemically synthesised [N33A] stromal cell-derived factor alpha, a potent ligand for the HIV-1 "fusin" coreceptor. Proc. Natl. Acad. Sci. USA. 95:6941-6946.

32. Tashiro, K., et al. 1993. Signal sequence trap: a cloning strategy for secreted proteins and Type1 membrane proteins. Science. 261:600-603.

33. Shibuta, K., et al. 1997. Reduced expression of the CXC chemokine hIRH/SDF-1 alpha mRNA in hepatoma and digestive tract cancer. Int. J. Cancer. 73:656-662.

34. Vicente-Manzanares, M., et al. 1998. The chemokine SDF-1 alpha triggers a chemotactic response and induces cell polarization in human B lymphocytes. Eur. J. Immunol. 28:2197-2207.

35. Wang, J.-F., Liu, Z.-Y., and Groopman, J.E. 1998. The $\alpha$ chemokine receptor CXCR4 is expressed on the megakaryocytic lineage from progenitor to platelets and modulates migration and adhesion. Blood. 92:756-764.

36. Nagasawa, T., et al. 1996. Defects of B cell lymphoiesis and bone marrow myelopoiesis in mice lacking the CXC chemokine PBSF/SDF. Nature. 382:635-638.

37. Tachibana, K., et al. 1998. The chemokine receptor CXCR4 is essential for vascularization of the gastrointestinal tract. Nature. 393:591-594.

38. Zou, Y.-R., Kottmann, A.H., Kuroda, M., Taniuchi, I., and Littman, D.R. 1998. Function of the chemokine receptor CXCR4 in haematopoesis and in cerebellar development. Nature. 393:595-599.

39. Jourdan, P., et al. 1998. IL-4 induces functional cell-surface expression of CXCR4 on human T cells. J. Immunol. 160:4153-4157.

40. Hesselgesser, J., et al. 1998. Neuronal apoptosis induced by HIV-1 gp120 and the chemokine SDF-1alpha is mediated by the chemokine receptor CXCR4. Curr. Biol. 8:595-598.

41. Herbein, G., et al. 1998. Apoptosis of CD8+ T cells is mediated by macrophages through interaction of HIV gp120 with the chemokine receptor CXCR4. Nature. 395:189-194.

42. Berndt, C., Möpps, B., Angermüller, S., Gierschik, P., and Krammer, P.H 1998. CXCR4 and CD4 mediate a rapid CD95-independent cell death in CD4 ${ }^{+}$T cells. Proc. Natl. Acad. Sci. USA. 95:12556-12561.

43. Bleul, C.C., et al. 1996. The lymphocyte chemoattractant SDF-1 is a ligand for LESTER/fusin and blocks HIV-1 entry. Nature. 382:829-832.

44. Oberlin, E., et al. 1996. The CXC chemokine SDF-1 is the ligand for LESTER/fusin and prevents infection by T-cell-line-adapted HIV-1. Nature. 382:833-835.

45. Harouse, J.M., et al. 1991. Inhibition of entry of HIV-1 into neural cell lines by antibodies against galactosylceramide. Science. 253:320-323.

46. Endres, M.J., et al. 1996. CD4-independent infection by HIV-2 is mediated by fusin/CXCR4. Cell. 87:745-751.

47. Dayanithi, G., Yahi, N., Baghdiguian, S., and Fantini, J. 1995. Intracellular calcium release induced by human immunodeficiency virus type 1 (HIV-1) surface envelope glycoprotein in human intestinal epithelial cells: a putative mechanism for HIV-1 enteropathy. Cell Calcium. 18:9-18.

48. Dwinell, M.B., Eckmann, L., Leopard, J.D., Varki, N.M., and Kagnoff, M.F. 1999. Chemokine receptor expression by human intestinal epithelial cells. Gastroenterology. 117:359-367. 